\title{
Emotional Experience and Recognition across Menstrual Cycle and in Premenstrual Disorder
}

\author{
Julieta Ramos-Loyo ${ }^{1} \&$ Araceli Sanz-Martin ${ }^{1}$ \\ ${ }^{1}$ Instituto de Neurociencias, Universidad de Guadalajara, Guadalajara, Jalisco, México \\ Correspondence: Araceli Sanz-Martin, Instituto de Neurociencias, Universidad de Guadalajara, Guadalajara, \\ Jalisco, México. E-mail: aracelisanz@yahoo.com
}

Received: September 8, 2017

Accepted: October 10, 2017 Online Published: October 17, 2017

doi:10.5539/ijps.v9n4p33

URL: http://doi.org/10.5539/ijps.v9n4p33

\begin{abstract}
The aim of this study was to determine if differences exist in mood and in the recognition of female and male emotional faces among women in different phases of the menstrual cycle, and in women who suffer from Premenstrual Dysphoric Disorder (PMDD) in the premenstrual phase. Both the emotional states and the recognition of female and male emotional faces were assessed in women in each phase of the menstrual cycle: post-menstrual, ovulatory, post-ovulatory and premenstrual. Also evaluated was a group of women who presented symptoms of PMDD during the premenstrual phase. Only the women with PMDD showed significant changes in levels of unpleasant emotions and anxiety. Regardless of group, the highest accuracy was observed for recognition of happiness and disgust, followed by surprise and sadness. The lowest level of recognition was seen for fear and anger. In addition, expressions of happiness and surprise were recognized better on female faces, while fearful and angry expressions were recognized better on male faces. Finally, women in the ovulatory phase and those with PMDD showed higher accuracy when recognizing sadness on male faces. These results suggest that only women with PMDD presented important differences in their emotional experience compared to the other groups. Finally, the gender of the emotion emitter was a factor that affected the recognition of emotions, an effect that was seen to interact slightly with the menstrual cycle phase.
\end{abstract}

Keywords: menstrual cycle, PMDD, emotional experience, mood, emotional recognition

\section{Introduction}

Many women experience significant emotional, cognitive and somatic changes during the menstrual cycle (Luine, 2014; Sundstrom Poromaa \& Gingnell, 2014). In the ovulatory and post-ovulatory phases, mood improvement (Dalton, 1969; Henderson \& Whissell, 1997), fewer aggressive responses to frustrating events (Krug, Finn, Pietrowsky, Fehm, \& Born, 1996), and an increase in sexual appetite have been documented (van Goozen, Frijda, Wiegant, Endert, \& Van de Poll, 1996). Also during the pre-ovulatory phase, women often have greater galvanic skin responses and report feeling more jealousy when hearing or imagining stories in which their partner interacts with another woman (Krug, Finn, Pietrowsky, Fehm, \& Born, 1996). Conversely, the premenstrual and menstrual phases tend to be characterized by increases in depression, irritability, anxiety and stress (Dalton, 1969; Henderson \& Whissell, 1997), though these emotional disturbances usually diminish -or disappear altogether- once the menstrual flow occurs. It is important to mention that suicide attempts are more frequent during the menstrual and premenstrual phases (Baca-García, Díaz-Sastre, de León, \& Saiz-Ruíz, 2000; Baca-García, Sánchez-González, González Díaz-Corralero, González García, \& de León, 1998).

However, observations of some women show that emotional changes in the premenstrual phase can be sufficiently severe to affect their normal interpersonal relationships or their school and work activities; these are women who suffer from Premenstrual Dysphoric Disorder (PMDD), which is relatively common in women of fertile ages (Sundstrom Poromaa \& Gingnell, 2014). It has been suggested that approximately $2-10 \%$ of women in child-bearing ages are afflicted by severe premenstrual symptoms, and $2-5 \%$ fulfill criteria for Premenstrual Dysphoric Disorder (PMDD) (O'Brien et al., 2011). Population-based epidemiological studies furthermore suggest that sub-threshold PMDD may be even more prevalent, found in $18 \%$ of women (Wittchen, Becker, Lieb, $\&$ Krause, 2002). This condition consists of a cluster of affective, behavioral and somatic symptoms that recur monthly during the premenstrual phase of the menstrual cycle and end shortly after menstruation begins. Symptoms of PMDD can be both physical and emotional, but those associated with mood predominate. The most 
debilitating symptoms are emotional in nature and include intense emotional lability, irritability, depression, anxiety, feelings of "loss of control", difficulty in concentrating, and fatigue. Physical symptoms include abdominal bloating, breast tenderness, headache and generalized aches, hypersomnia and insomnia, and changes in appetite or cravings for specific foods (American-Psychatric-Association, 2014). Henderson and Whissell (1997) found that only women classified as "sufferers" of premenstrual discomfort presented significant mood swings during the premenstrual phase.

In addition to observations of emotional experiences, some authors have found differences in emotional recognition during the menstrual cycle. For example, Derntl, Kryspin-Exner, Fernbach, Moser, and Habel (2008) evaluated emotional recognition in women in the follicular (days 1-14) or luteal phase (days 15-20) and determined that those in the former had better performance than those in the latter. However, they found no interaction between emotions and menstrual phases. In a later study, these researchers (Derntl, Hack, Kryspin-Exner, \& Habel, 2013) found that although women in follicular phase has higher emotional recognition accuracy than women in midluteal phase, this last group presents a significant difference in reaction times, with faster responses for sad and angry stimuli. In addition, they found significant correlations between progesterone levels and emotion recognition accuracy and affective responsiveness only in the luteal group. These findings are corroborated by a report on decreased facial recognition accuracy up on acute progesterone administration (van Wingen et al., 2007). Women also demonstrate a greater tendency to perceive fearful expressions (with averted as compared to direct gaze) as more intense if progesterone levels are high (Conway et al., 2007), and respond faster to sad and angry situations or sad faces in the mid-luteal phase (Derntl et al., 2013; Gasbarri et al., 2008), as well as to other aversive stimuli, such as snakes (Masataka \& Shibasaki, 2012). In their study, Pearson and Lewis (2005) assessed the ability to recognize emotional expressions in women in the four phases of the menstrual cycle. They found that the recognition of fear expressions was better in women in the ovulatory phase than those in the menstrual phase. However, those studies did not control for the presence of PMDD symptoms in participants. In contrast, Rubinow et al. (2007) compared emotional recognition between women with and without PMDD, in the follicular and late luteal phases. They found that during the luteal phase, women with PMDD had lower accuracy than in other phases, and that they more often mistook neutral faces for sad and happy ones.

It has also been suggested that recognition of facial emotions is influenced by the gender of the emitter; that is, the person who expresses the emotion. In this regard, Hugdahl, Iversen and Johnsen (1993) tested differences in emotional recognition of happy, angry and neutral expressions when expressed by men vs. women. They found that subjects showed greater accuracy when identifying anger expressed by men than by women, and that happy expressions on women's faces were recognized more quickly than any of the other stimuli. In another study, Rahman, Wilson and Abrahams (2004) measured accuracy and speed in the identification of happy, surprised and neutral expressions in heterosexual and homosexual individuals. They found that, regardless of their sexual orientation and the emotion expressed, women identified male faces more correctly than female ones. Erwin (1992), meanwhile, observed that women were more sensitive to happy and sad emotional expressions on male faces than female ones. In contrast to previous authors, Orozco and Ehlers (1998) obtained shorter responses when their subjects were asked to identify sad expressions in females compared to males.

In conclusion, many women have been described as presenting changes in their emotional states during the menstrual cycle, especially those who suffer Premenstrual Dysphoric Disorder (PMDD). In addition to changes in emotional states, some studies have reported differences in the ability to recognize emotional facial expressions in relation to the phases of the menstrual cycle. However, we do not know whether these differences could be affected by the gender of the emotion emitter, and if this effect is greater in women with PMDD, especially in relation to negative emotions, similar to findings published on patients with depression or anxiety (Mandal \& Bhattacharya, 1985). Given this background, the aim of the present study was to determine the existence of differences in mood and in the recognition of female and male emotional faces among women in different phases of the menstrual cycle and with PMDD in the premenstrual phase, while also considering the gender of the emitter of the emotions.

\section{Method}

\subsection{Participants}

A total of 69 right-handed women aged 19-23 years volunteered to participate in the study. They all underwent a structured interview immediately before testing to determine their health status and history of normal, regular menstrual cycles. None reported any previous brain disease, psychopathology, or neural injury, nor were they taking any type of medication, oral contraceptives, or other hormonal treatment in the 6 months prior to testing. 
Finally, none had been pregnant. All women completed a modified version of the Menstrual and Premenstrual Symptoms Questionnaire (Chesney \& Tasto, 1975).

Subjects were tested in one of four different phases of the menstrual cycle: postmenstrual (POM, days 6-9), ovulatory (OVU, days 12-15), postovulatory (POVU, days 18-23), and premenstrual (PREM, days 25-28). To determine the menstrual cycle phase, each participant was initially asked about the length of her cycle and the starting day of her previous menstruation. Based on these data, a tentative schedule of the days was set to cover each menstrual phase, including any necessary corrections for cases in which the menstrual cycle was not 28 days in length. Subsequently, the date of menstruation after the experiment was verified, and those women whose cycle did not match the estimated date were eliminated from the sample (11 participants).

The data from the remaining 58 women were included in the analyses. The mean age of these subjects was 19.41 years (SEM=1.4). Of these women, 48 had no symptoms of PMDD and were classified in the following four groups according to their menstrual phase: a) POM ( $n=12)$; b) OVU (n=13); c) POVU (n=13); and, d) PREM $(n=10)$. Finally, a fifth group of 10 participants with PMDD symptoms was evaluated in the premenstrual phase (PMDD).

The study was approved by the Ethics Committee of the Neuroscience Institute and complied fully with the ethical standards of the American Psychological Association (APA). Subjects were only allowed to participate after giving their informed consent.

\subsection{Emotional States}

The Emotional State Scale (Ramos et al., 1996) was applied to assess participants' mood. This scale consisted of 25 adjectives that described both pleasant (i.e., happy, peaceful) and unpleasant (i.e., angry, sad) emotions, as well as words related to the perceived arousal level (i.e., sweaty, tense). For each item, participants were instructed to make a mark on a $10-\mathrm{cm}$ line to indicate the intensity of their emotional state. The left end of the line indicated absence of the emotion, while the right end represented maximum intensity.

\subsection{Emotional Recognition}

To assess emotional recognition, 6 "odd-ball” tasks were applied. In each one, 220 black-and-white photographs of the faces of 10 different people ( 5 women, 5 men) (Ekman \& Friesen, 1975) were shown. All photos measured 147 $\times 232$ pixels and were displayed in the center of a computer monitor against a black background. The duration of each stimulus was $500 \mathrm{~ms}$; the inter-stimuli interval varied from 750-1125 ms. Tasks were presented on a PC with the software ESTIMVIS (Guevara, Ramos, Sanz-Martin, \& Hernández-González, 2004). Participants had to press a key each time the target stimulus appeared (40 stimuli). On each task, the target was a specific facial emotion -happiness, anger, fear, surprise, disgust or sadness- or a neutral expression.

\subsection{Procedure}

Participants were assessed in a shielded, dimly-lit room. For the emotional recognition task, they were seated in a comfortable position approximately $60 \mathrm{~cm}$ from the computer screen. Before each task, they performed a short training session to ensure that they understood the instructions. There was a 2-min rest interval after each task. The order of the tasks was counterbalanced among participants. Each experimental session lasted about an hour and a half.

\subsection{Statistical Analysis}

A principal component analysis, using the Varimax rotation, was performed to reduce the number of variables that composed the Emotional State Scale. Later, to determine inter-group differences, ANOVAs were performed with the rotated component scores of the five main components obtained. Three-way ANOVAs were performed for correct responses and reaction times to detect differences in performance between groups, type of emotion, and the gender of the emitter. To determine the interaction between groups and emitter on each emotional task, two-factor ANOVAs (group $\times$ emitter) were conducted. Post-hoc comparisons (Bonferroni corrections) were applied for pairwise comparisons. The $p$ value for significance was set at 0.05 . All data had a normal distribution, therefore Greenhouse corrections were not necessary. 


\section{Results}

\subsection{Emotional States}

Five eigen vectors explained a $64 \%$ of total variance and grouped adjectives which described negative and positive emotional states, fatigue, anxiety/arousal, and boredom (Table 1). The first component comprised adjectives that indicate unpleasant states such as upset, tense, disgusted, sad and discouraged and, with the opposite sign, fulfilled and free. On the contrary, in the second component adjectives related to pleasant states were grouped such as cheerful, alive, fulfilled and inspired. The third component pointed out low energetic negative adjectives such as depressed, tired, sorry and asleep. In the fourth component adjectives related to anxiety such as tense, accelerated, anxious, scared as well as high peripheral arousal perception as increase in heart rate, breathing rate, sweating and muscle tension were included. Finally, the fifth component was formed by apathetic unpleasant adjectives such as indifferent, irked and bored.

Table 1. Principal component analysis of the Emotional State Scale

\begin{tabular}{|c|c|c|c|c|c|}
\hline & 1. Anxiety/arousal & 2. Negative mood & 3. Fatigue & 4. Positive mood & 5. Boredom \\
\hline Attentive & -.46 & .003 & .093 & -.447 & -.254 \\
\hline Cheerful & -.032 & -.164 & -.345 & $-.676^{*}$ & -.032 \\
\hline Peaceful & -.365 & -.085 & -.093 & -.427 & .473 \\
\hline Alive & .132 & -.246 & -.469 & $-.531 *$ & -.018 \\
\hline Fulfilled & -.118 & $-.512 *$ & -.178 & $-.567^{*}$ & .104 \\
\hline Inspired & .202 & .079 & .251 & $-.714 *$ & -.18 \\
\hline Free & -.087 & $-.538^{*}$ & -.25 & -.436 & .277 \\
\hline Apathetic & .308 & .187 & .33 & .30 & .464 \\
\hline Irked & .233 & .375 & .385 & .048 & $.528^{*}$ \\
\hline Upset & .126 & $.819^{*}$ & .135 & .023 & .236 \\
\hline Tense & $.505^{*}$ & $.644^{*}$ & .165 & .119 & .142 \\
\hline Disgusted & .127 & $.874 *$ & .163 & .074 & .149 \\
\hline Indifferent & .259 & -.081 & .191 & .003 & $.574 *$ \\
\hline Sad & .32 & $.627 *$ & .364 & .185 & -.253 \\
\hline Depressed & .391 & .415 & $.616^{*}$ & .096 & -.096 \\
\hline Tired & -.041 & .248 & $.682 *$ & .016 & .223 \\
\hline Anxious & $.704 *$ & .328 & .254 & .195 & .189 \\
\hline Sorry & .096 & .222 & $.754 *$ & .123 & .239 \\
\hline Scared & $.578^{*}$ & .343 & .046 & .047 & .204 \\
\hline Bored & .243 & .288 & .083 & .177 & $.531 *$ \\
\hline Asleep & .047 & .068 & $.906^{*}$ & .035 & .051 \\
\hline Accelerated & $.838^{*}$ & -.015 & -.056 & -.038 & .003 \\
\hline Discouraged & .097 & $.822 *$ & .18 & .068 & .079 \\
\hline Melancholic & .482 & .469 & .361 & .069 & -.261 \\
\hline Heart rate & $.846^{*}$ & .075 & .038 & -.002 & -.001 \\
\hline Breathing & $.853^{*}$ & .134 & .064 & -.065 & .126 \\
\hline Sweating & $.636^{*}$ & .073 & .083 & -.089 & .192 \\
\hline Muscle tension & $.618^{*}$ & .366 & .075 & .114 & .061 \\
\hline percentage of explained variance & $18.78 \%$ & $16.9 \%$ & $12.51 \%$ & $8.65 \%$ & $7.16 \%$ \\
\hline Cumulative variance & $18.78 \%$ & $35.68 \%$ & $48.19 \%$ & $56.84 \%$ & $64 \%$ \\
\hline
\end{tabular}

* Correlation $\mathrm{p}<0.05$. 
The ANOVAs performed with the component scores revealed differences among groups in the first $\left(\mathrm{F}_{4,53}=3.67\right.$, $\left.\mathrm{p}=.01, \eta \mathrm{P}^{2}=.21\right)$ and second components $\left(\mathrm{F}_{4,53}=2.18, \mathrm{p}=.03, \eta \mathrm{P}^{2}=.17\right)$. PMDD participants presented higher scores for the emotional states related to anxiety and arousal (component 1 ) than those without the disorder in the POM $(\mathrm{p}<.04)$, OVU $(\mathrm{p}<.03)$ and PREM phases $(\mathrm{p}<.01)$. They also showed higher scores for states related to unpleasant emotions (component 2 ) than women without this disorder in the PREM phase $(\mathrm{p}<.05)$ (Figure 1).

\section{Component 1: Anxiety and Arousal}

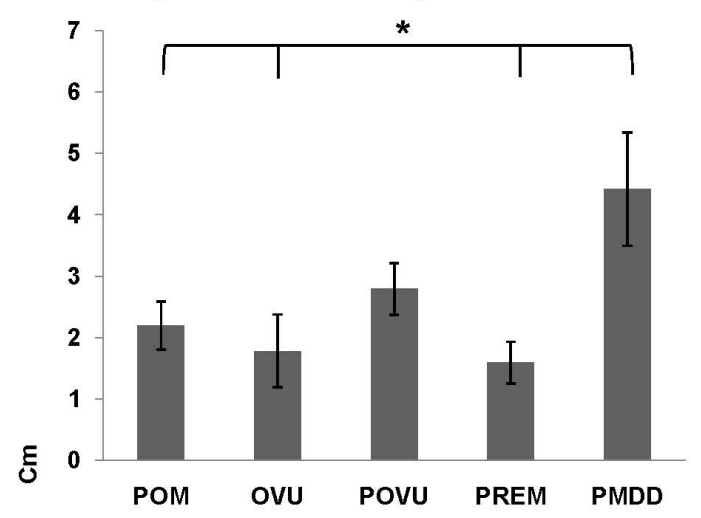

Component 2: Negative Mood

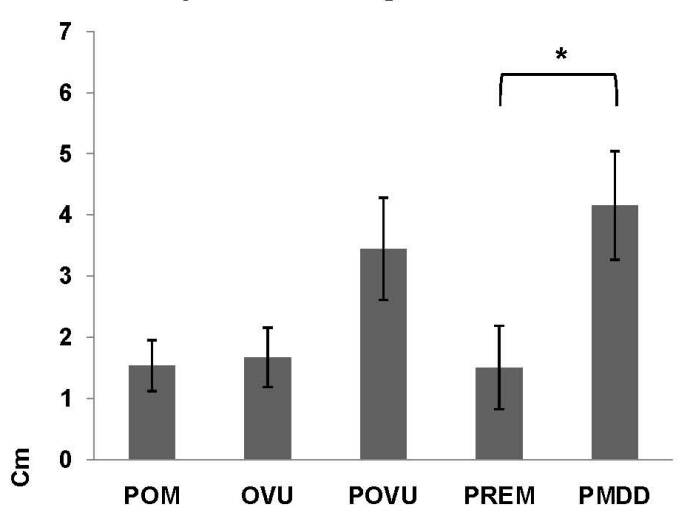

Figure 1. Means ( \pm standard errors) of the raw scores for the emotional states included in principal components 1 and 4 in each group (POM, postmenstrual phase; OVU, ovulatory phase; POVU, postovulatory phase; PREM, premenstrual phase; and PMDD, premenstrual phase with PMDD)

* indicates significant differences between groups $(\mathrm{p}<0.05)$.

\subsection{Emotional Recognition}

The ANOVAs for correct responses revealed a principal effect of emotion $\left(\mathrm{F}_{5,265}=62.96, \mathrm{p}<.001, \eta \mathrm{P}^{2}=.54\right)$ together with an interaction between emotion and the gender of the emitter $\left(\mathrm{F}_{5,265}=10.11, \mathrm{p}<.001, \eta \mathrm{P}^{2}=.16\right)$. As Figure 2 shows, participants had more correct responses on the happiness and disgust tasks, followed by surprise and sadness. Lowest performance was obtained on the fear and anger tasks. Regarding emotion-emitter interaction, the post hoc analysis showed that participants had more correct responses when fear was expressed by a male than by a female face. However, when happiness and surprise were expressed by female faces, accuracy was higher than for the male faces (Figure 2, Table 2).
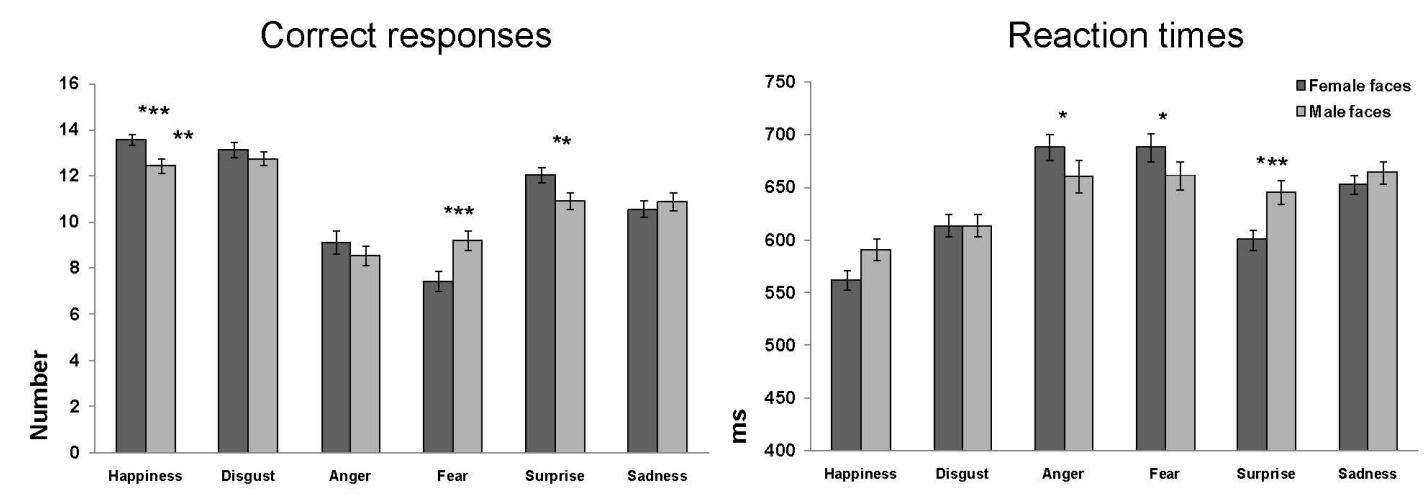

Figure 2. Number of correct responses and reaction times (mean \pm standard error) for each emotion expressed by females and males. Asterisks indicates significant differences when the emotion was expressed by female $v s$. male emitters

${ }^{* * *} \mathrm{p}<.000,{ }^{* *} \mathrm{p}<.001, * \mathrm{p}<.05$. 
Table 2. Significance $(p)$ of the Bonferroni comparisons of the correct responses and reaction times among emotions

\begin{tabular}{|c|c|c|c|c|c|c|}
\hline & Happiness & Disgust & Anger & Fear & Surprise & Sadness \\
\hline \multicolumn{7}{|l|}{ Correct responses } \\
\hline Happiness & & 1,000 & 0,001 & 0,001 & 0,001 & 0,001 \\
\hline Disgust & 1,000 & & 0,001 & 0,001 & 0,001 & 0,001 \\
\hline Anger & 0,001 & 0,001 & & 1,000 & 0,001 & 0,001 \\
\hline Fear & 0,001 & 0,001 & 1,000 & & 0,001 & 0,001 \\
\hline Surprise & $\mathbf{0 , 0 0 1}$ & 0,001 & $\mathbf{0 , 0 0 1}$ & 0,001 & & 0,043 \\
\hline Sadness & $\mathbf{0 , 0 0 1}$ & 0,001 & $\mathbf{0 , 0 0 1}$ & 0,001 & 0,043 & \\
\hline \multicolumn{7}{|l|}{ Reaction times } \\
\hline Happiness & & ,001 & ,001 &, 001 &, 001 & ,001 \\
\hline Disgust &, 001 & &, 001 &, 001 & 1 &, 001 \\
\hline Anger &, 001 & ,001 & & 1 &, 001 & 1 \\
\hline Fear &, 001 &, 001 & 1 & &, 001 & ,913 \\
\hline Surprise & ,001 & 1 & ,001 & ,001 & & ,002 \\
\hline Sadness & ,001 &, 001 & 1 & ,913 &, 002 & \\
\hline
\end{tabular}

ANOVAs also showed an interaction between groups and emitters on the sadness task $\left(\mathrm{F}_{5,53}=3.11, \mathrm{p}<.022\right.$, $\eta \mathrm{P}^{2}=.19$ ), as accuracy was higher in the OVU and PMDD groups when sadness was expressed by males than females (Figure 3).

\section{Correct responses in sadness}

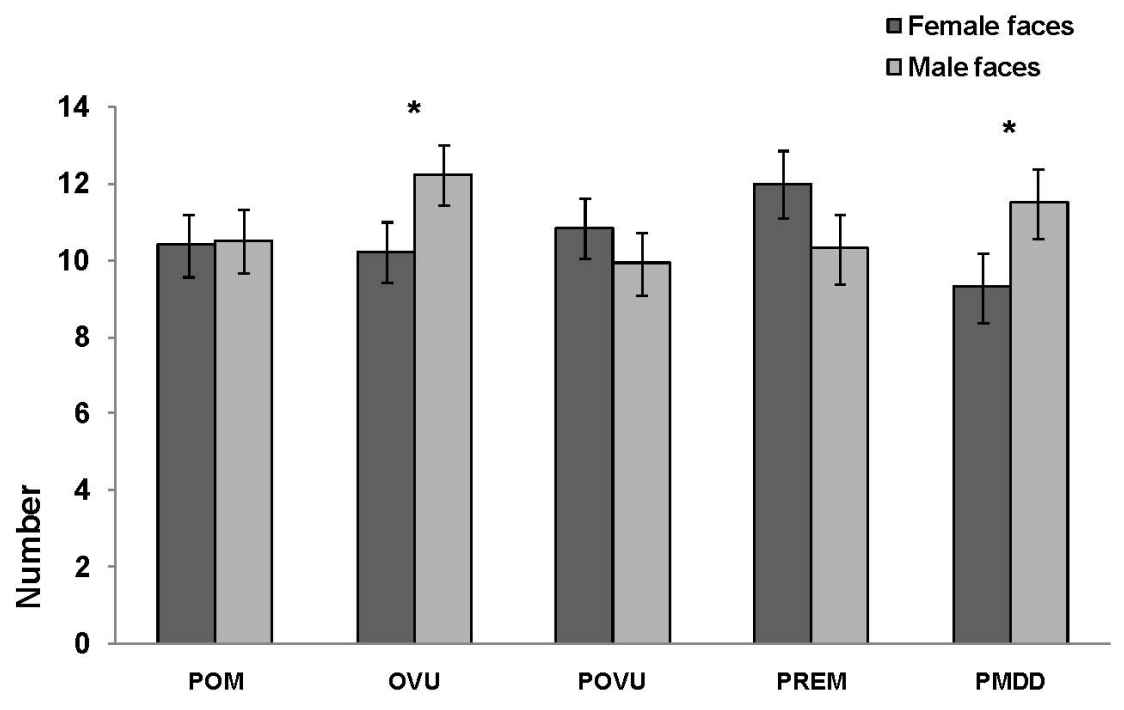

Figure 3. Number of correct responses (mean \pm standard error) on the sadness task for female and male emitters in each group (POM, postmenstrual phase; OVU, ovulatory phase; POVU, postovulatory phase; PREM, premenstrual phase; and PMDD, premenstrual phase with PMDD)

* indicates significant differences when the emotion was expressed by female $v s$. male emitters $(\mathrm{p}<0.05)$.

Regarding reaction times, there was a principal effect of emotion $\left(\mathrm{F}_{5,260}=35.58, \mathrm{p}<.0001, \eta \mathrm{P}^{2}=.54\right)$, and an interaction between emotion and emitter $\left(\mathrm{F}_{5,260}=9.88, \mathrm{p}<.001, \eta \mathrm{P}^{2}=.16\right.$ ) (Table 2). Participants had shorter reaction 
times when responding to happiness, disgust and surprise, followed by sadness, fear and anger. The post hoc analysis for emotion $\times$ emitter interaction showed that participants had shorter reaction times for male than female faces with expressions of anger and fear, but vice versa for expressions of surprise (Figure 2).

\section{Discussion}

This study reveals that women with significant symptoms of PMDD in the PREM phase presented higher levels of anxiety and unpleasant emotions compared to those without PMDD symptoms in any phase. It further shows that the ability to recognize emotional expressions on female $v s$. male faces can vary according to menstrual phase and the gender of the emitter.

\subsection{Emotional States}

Principal component analysis made it possible to group the emotional states in five categories (pleasant and unpleasant emotions, fatigue, anxiety-arousal, and boredom); two of which presented significant differences among groups. We found that women with PMDD presented higher intensities of states related to unpleasant emotions and anxiety than those without this disorder in any menstrual phase; however, there were no significant differences among menstrual phases in the intensity of the emotional states of the women without PMDD. Though some authors have found that women in the premenstrual and menstrual phases show increased depression, irritability, anxiety and stress (Dalton, 1969; Henderson \& Whissell, 1997), others (Henderson \& Whissell, 1997) report that only women classified as "sufferers" of premenstrual discomfort presented significant mood swings which agree with our findings.

The higher scores for anxiety and unpleasant emotions in women with PMDD could be a consequence of their greater sensitivity to the decrease in estrogen and progesterone levels in the premenstrual phase (Rapkin et al., 1997). Given that ovarian steroids have direct effects on neurotransmission, this hormonal decline could modify the function of the serotonergic, GABAergic and noradrenergic systems, all of which are involved in mood regulation (Gurguis, Yonkers, Blakeley, et al., 1998; Gurguis, Yonkers, Phan, et al., 1998; Halbreich et al., 1996; Rapkin et al., 1997; Rubinow, Schmidt, \& Roca, 1998; Sundstrom, Ashbrook, \& Backstrom, 1997).

In women without PMDD, a relation between the excitatory effects of estrogen and the expression of positive emotions or mood improvement during the follicular phase has been described (Henderson \& Whissell, 1997). However, this relation is lost during the luteal phase due to the rise and fall of estrogen and progesterone levels, which result in negative emotions (Bancroft \& Backstrom, 1985; Henderson \& Whissell, 1997). This effect adds to the idea that women with PMDD could be more sensitive to decreases in estrogen levels.

On other hand, women with PMDD show an abnormal bold activation in brain areas involved to emotional processing as amygdala, ventral striatum and prefrontal cortex. Protopopescu et al. (2008) found that women with PMDD in the premenstrual phase, showed an increased amygdala response to negative vs. neutral stimuli, and a decreased ventral striatum response to positive vs. neutral stimuli compared with asymptomatic subjects.

\subsection{Emotional Recognition}

Our results support the existence of differences in recognizing the six basic facial emotions. Emotions like happiness, disgust and surprise clearly showed better recognition, with a higher number of correct responses and shorter reaction times. In contrast, fear and anger obtained the lowest number of correct responses and the longest reaction times. Our findings thus coincide with those from previous studies that observed greater accuracy in detecting happiness than expressions of fear (Juth, Lundqvist, Karlsson, \& Ohman, 2005; Kirouac \& Dore, 1983), anger (Becker, Anderson, Mortensen, Neufeld, \& Neel, 2011; Becker et al., 2012; Juth et al., 2005), and sadness (Srivastava \& Srinivasan, 2010). These findings have led researchers to postulate that happy facial expressions are more visually-discriminable, probably because their communicative intent is less ambiguous than that of other expressions (Becker et al., 2011).

In addition, the present study found differences in emotional recognition as a function of the gender of the emitter. Regardless of the phase of the menstrual cycle, women showed more correct responses when expressions of fear were represented by male faces, whereas happiness and surprise were recognized more accurately in female faces. Moreover, participants showed shorter reaction times when anger and fear were expressed by male faces, though the opposite was true for surprise, where female faces generated shorter times. Similar results have been reported by (Hugdahl et al., 1993). Some authors have attempted to explain such differences in emotional recognition by applying an evolutionary perspective. For example, Öhman and Dimberg (1978) consider that in most societies men are still more dominant and aggressive than women; hence, it is adaptively important both for men and women to decipher negative, non-verbal emotional messages produced by men. 
In other findings, happiness and surprise were recognized more accurately when expressed by women. A possible explanation could be that women show affection and care for others to a greater extent than men; therefore, people in general are more used to seeing happiness in females right from birth. Studies have shown that Japanese and UK students prefer feminized faces, which in turn receive more positive personality attributes (e.g., cooperation, honesty, good parenting) (Perrett et al., 1998), while others have found that male faces are associated with dominance (Perrett et al., 1998). Hence, anger and fear could be more relevant when expressed by men than by women.

In our work, in agreement with Erwin et al.'s study (1992), we found differences between the recognition of sadness depending on the gender of the emitter, but we also observed that this can depend on the phase of the menstrual cycle and the presence of PMDD. Both women during ovulation and with PMDD showed higher accuracy in recognizing male than female sadness compared to the other groups. However, we consider that the reasons may differ in each group. First, it is probable that higher accuracy in recognizing sadness in male faces in the OVU group may be a consequence of cyclical changes in sensitivity to stimuli associated with reproductive relevance. In this regard, Penton-Voak and Perrett (2000) observed that women in the follicular phase (i.e., when fertile) prefer more masculinized faces than when they are in the luteal phase. Macrae, Alnwick, Milne, and Schloerscheidt (2002) also suggested that in the follicular phase women made better cognitive judgments about men. Those authors found that women in the follicular phase classified male faces or a word stereotypically associated with men (e.g., arrogant, hairy and brave) more quickly than in the luteal phase. Likewise, Frost (1994) observed that women in the ovulatory phase evaluated darker male faces (more manly) more positively than when in other phases of the cycle.

As mentioned above, women with PMDD also showed a higher number of correct responses when recognizing sadness in male faces. We consider that this result could be explained by the mood of this group of women. As we reviewed in previous paragraphs, women with PMDD experience greater intensity of both unpleasant emotions and anxiety. In this regard, studies have found that patients with depression or anxiety show better recognition of sadness (Mandal \& Bhattacharya, 1985). Thus, women with PMDD may recognize male sadness more accurately because they are in "emotional attunement" with them.

Finally, it is important to note that in addition to the significant differences in sadness, we expected to find between-group differences in relation to other emotions as well -especially fear and angry- as other authors have reported (Conway et al., 2007; Derntl et al., 2013; Gasbarri et al., 2008; Pearson \& Lewis, 2005). In contrast to that study, however, our research found that all five groups generated similar performance for all emotions except sadness. We consider that this result could be due to the great variability that occurred within each group. Such intragroup variability could have been mitigated by an experimental design in which each woman was assessed in the different stages of her menstrual cycle. However, in such an approach it would be difficult to avoid the effect of learning and/or habituation.

In conclusion, the results of the present study indicate that only women with PMDD showed differences in the levels of unpleasant emotions and anxiety during the premenstrual phase compared to women without the disorder. However, the latter, when evaluated in different phases of the cycle, did not present differences in relation to the emotional states. Also, women recognized happiness and surprise more accurately when they were expressed by other women, but identified fear and anger more accurately when they were expressed by men. Women in the ovulatory phase and with PMDD in the premenstrual phase showed greater accuracy when recognizing sadness in male faces. These results suggest that the gender of the emotion emitter was a factor that affected the recognition of the emotions, and that this effect may interact slightly with the phase of the menstrual cycle.

\section{Acknowledgments}

The authors thank Paul Kersey for correcting the English version of the manuscript and Miguel Angel Guevara for technical assistance.

\section{References}

American-Psychatric-Association. (2014). Manual diagnóstico y estadístico de los trastornos mentales: DSM-5. España: Editorial Médica Panamericana.

Baca-García, E., Díaz-Sastre, C., de León, J., \& Saiz-Ruíz, J. (2000). The relationship between menstrual cycle phases and suicide attempts. Psychosomatic Medicine, 62(1), 50-60. https://doi.org/10.1097/00006842-200001000-00008 
Baca-García, E., Sánchez-González, A., González Díaz-Corralero, P., González García, I., \& de León, J. (1998). Menstrual cycle and profiles of suicidal behaviour. Acta Psychiatrica Scandinavica, 97(1), 32-35. https://doi.org/10.1111/j.1600-0447.1998.tb09959.x

Bancroft, J., \& Backstrom, T. (1985). Premenstrual syndrome. Clinical Endocrinology (Oxf), 22(3), 313-336. https://doi.org/10.1111/j.1365-2265.1985.tb03244.x

Becker, D. V., Anderson, U. S., Mortensen, C. R., Neufeld, S. L., \& Neel, R. (2011). The face in the crowd effect unconfounded: Happy faces, not angry faces, are more efficiently detected in single- and multiple-target visual search tasks. Journal of Experimental Psychology: General, 140(4), 637-659. https://doi.org/10.1037/a0024060

Becker, D. V., Neel, R., Srinivasan, N., Neufeld, S., Kumar, D., \& Fouse, S. (2012). The vividness of happiness in dynamic facial displays of emotion. PLoS One, 7(1), e26551. https://doi.org/10.1371/journal.pone.0026551

Chesney, M. A., \& Tasto, D. L. (1975). The effectiveness of behavior modification with spasmodic and congestive

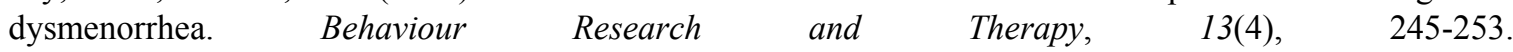
https://doi.org/10.1016/0005-7967(75)90029-7

Conway, C. A., Jones, B. C., DeBruine, L. M., Welling, L. L., Law Smith, M. J., Perrett, D. I., ... Al-Dujaili, E. A. (2007). Salience of emotional displays of danger and contagion in faces is enhanced when progesterone levels are raised. Hormones and Behavior, 51(2), 202-206. https://doi.org/10.1016/j.yhbeh.2006.10.002

Dalton, K. (1969). The Menstrual Cycle. Hardmondsworth, Ingland: Pinguin Books LTD.

Derntl, B., Hack, R. L., Kryspin-Exner, I., \& Habel, U. (2013). Association of menstrual cycle phase with the core components of empathy. Hormones and Behavior, 63(1), 97-104. https://doi.org/10.1016/j.yhbeh.2012.10.009

Derntl, B., Kryspin-Exner, I., Fernbach, E., Moser, E., \& Habel, U. (2008). Emotion recognition accuracy in healthy young females is associated with cycle phase. Hormones and Behavior, 53(1), 90-95. https://doi.org/10.1016/j.yhbeh.2007.09.006

Ekman, P., \& Friesen, W. (Eds.). (1975). Unmasking the face. Englewood Cliffs: Prentice-Hall.

Erwin, R. J., Gur, R. C., Gur, R. E., Skolnick, B., Mawhinney-Hee, M., \& Smailis, J. (1992). Facial emotion discrimination: I. Task construction and behavioral findings in normal subjects. Psychiatry Research, 42(3), 231-240. https://doi.org/10.1016/0165-1781(92)90115-J

Frost, P. (1994). Preference for darker faces in photographs at different phases of the menstrual cycle: Preliminary assessment of evidence for a hormonal relationship. Perceptual and Motor Skills, 79(1 Pt 2), 507-514. https://doi.org/10.2466/pms.1994.79.1.507

Gasbarri, A., Pompili, A., d'Onofrio, A., Cifariello, A., Tavares, M. C., \& Tomaz, C. (2008). Working memory for emotional facial expressions: Role of the estrogen in young women. Psychoneuroendocrinology, 33(7), 964-972. https://doi.org/10.1016/j.psyneuen.2008.04.007

Guevara, M. A., Sanz-Martin, A., Ramos, J., \& Hernández-González, M. (2004). ESTIMVIS: Un sistema computarizado para estimulación visual. Revista Mexicana de Ingeniería Biomédica, 25(1), 52-59.

Gurguis, G. N., Yonkers, K. A., Blakeley, J. E., Phan, S. P., Williams, A., \& Rush, A. J. (1998). Adrenergic receptors in premenstrual dysphoric disorder. II. Neutrophil beta2-adrenergic receptors: Gs protein coupling, phase of menstrual cycle and prediction of luteal phase symptom severity. Psychiatry Research, 79(1), 31-42. https://doi.org/10.1016/S0165-1781(98)00025-0

Gurguis, G. N., Yonkers, K. A., Phan, S. P., Blakeley, J. E., Williams, A., \& Rush, A. J. (1998). Adrenergic receptors in premenstrual dysphoric disorder: I. Platelet alpha 2 receptors: Gi protein coupling, phase of menstrual cycle, and prediction of luteal phase symptom severity. Biological Psychiatry, 44(7), 600-609. https://doi.org/10.1016/S0006-3223(98)00097-3

Halbreich, U., Petty, F., Yonkers, K., Kramer, G. L., Rush, A. J., \& Bibi, K. W. (1996). Low plasma gamma-aminobutyric acid levels during the late luteal phase of women with premenstrual dysphoric disorder. American Journal of Psychiatry, 153(5), 718-720. https://doi.org/10.1176/ajp.153.5.718

Henderson, B. J., \& Whissell, C. (1997). Changes in women's emotions as a function of emotion valence, self-determined category of premenstrual distress, and day in the menstrual cycle. Psychological Reports, 80(3 Pt 2), 1272-1274. https://doi.org/10.2466/pr0.1997.80.3c.1272 
Hugdahl, K., Iversen, P. M., \& Johnsen, B. H. (1993). Laterality for facial expressions: Does the sex of the subject interact with the sex of the stimulus face? Cortex, 29(2), 325-331. https://doi.org/10.1016/S0010-9452(13)80185-2

Juth, P., Lundqvist, D., Karlsson, A., \& Ohman, A. (2005). Looking for foes and friends: Perceptual and emotional factors when finding a face in the crowd. Emotion, 5(4), 379-395. https://doi.org/10.1037/1528-3542.5.4.379

Kirouac, G., \& Dore, F. Y. (1983). Accuracy and latency of judgment of facial expressions of emotions. Percept Mot Skills, 57(3 Pt 1), 683-686. https://doi.org/10.2466/pms.1983.57.3.683

Krug, R., Finn, M., Pietrowsky, R., Fehm, H. L., \& Born, J. (1996). Jealousy, general creativity, and coping with social frustration during the menstrual cycle. Archives of Sexual Behavior, 25(2), 181-199. https://doi.org/10.1007/BF02437935

Luine, V. N. (2014). Estradiol and cognitive function: Past, present and future. Hormones and Behavior, 66(4), 602-618. https://doi.org/10.1016/j.yhbeh.2014.08.011

Macrae, C. N., Alnwick, K. A., Milne, A. B., \& Schloerscheidt, A. M. (2002). Person perception across the menstrual cycle: Hormonal influences on social-cognitive functioning. Psychological Science, 13(6), 532-536. https://doi.org/10.1111/1467-9280.00493

Mandal, M. K., \& Bhattacharya, B. B. (1985). Recognition of facial affect in depression. Perceptual and Motor Skills, 61(1), 13-14. https://doi.org/10.2466/pms.1985.61.1.13

Masataka, N., \& Shibasaki, M. (2012). Premenstrual enhancement of snake detection in visual search in healthy women. Scientific Reports, 2, 307. https://doi.org/10.1038/srep00307

O’Brien, P. M. S., Bäckström, T., Brown, C., Dennerstein, L., Endicott, J., Epperson, C. N., ... Panay, N. (2011). Towards a consensus on diagnostic criteria, measurement and trial design of the premenstrual disorders: The ISPMD Montreal consensus. Archives of Women's Mental Health, 14(1), 13-21. https://doi.org/10.1007/s00737-010-0201-3

Öhman, A., \& Dimberg, U. (1978). Facial expressions as conditioned stimuli for electrodermal responses: A case of "preparedness"? Journal of Personality and Social Psychology, 36(11), 1251-1258. https://doi.org/10.1037/0022-3514.36.11.1251

Orozco, S., \& Ehlers, C. L. (1998). Gender differences in electrophysiological responses to facial stimuli. Biological Psychiatry, 44(4), 281-289. https://doi.org/10.1016/S0006-3223(97)00487-3

Pearson, R., \& Lewis, M. B. (2005). Fear recognition across the menstrual cycle. Hormones and Behavior, 47(3), 267-271. https://doi.org/10.1016/j.yhbeh.2004.11.003

Penton-Voak, I. S., \& Perrett, D. I. (2000). Female preference for male faces changes cyclically: Further evidence. Evolution and Human Behavior, 21, 39-48. https://doi.org/10.1016/S1090-5138(99)00033-1

Perrett, D. I., Lee, K. J., Penton-Voak, I., Rowland, D., Yoshikawa, S., Burt, D. M., ... Akamatsu, S. (1998). Effects of sexual dimorphism on facial attractiveness. Nature, 394(6696), 884-887. https://doi.org/10.1038/29772

Protopopescu, X., Tuescher, O., Pan, H., Epstein, J., Root, J., Chang, L., ... Silbersweig, D. (2008). Toward a functional neuroanatomy of premenstrual dysphoric disorder. Journal of Affective Disorders, 108(1-2), 87-94. https://doi.org/10.1016/j.jad.2007.09.015

Rahman, Q., Wilson, G. D., \& Abrahams, S. (2004). Sex, sexual orientation, and identification of positive and negative facial affect. Brain and Cognition, 54(3), 179-185. https://doi.org/10.1016/j.bandc.2004.01.002

Ramos, J., Corsi-Cabrera, M., Guevara, M. A., Arce, C., del Río, Y., \& Amezcua, C. (1996). Evaluación de estados emocionales producidos por la música. Revista Mexicana de Psicología, 13(2), 131-145.

Rapkin, A. J., Morgan, M., Goldman, L., Brann, D. W., Simone, D., \& Mahesh, V. B. (1997). Progesterone metabolite allopregnanolone in women with premenstrual syndrome. Obstetrics \& Gynecology, 90(5), 709-714. https://doi.org/10.1016/S0029-7844(97)00417-1

Rubinow, D. R., Schmidt, P. J., \& Roca, C. A. (1998). Estrogen-serotonin interactions: Implications for affective regulation. Biological Psychiatry, 44(9), 839-850. https://doi.org/10.1016/S0006-3223(98)00162-0

Srivastava, P., \& Srinivasan, N. (2010). Time course of visual attention with emotional faces. Attention Percepttion \& Psychophysics, 72(2), 369-377. https://doi.org/10.3758/APP.72.2.369 
Sundstrom Poromaa, I., \& Gingnell, M. (2014). Menstrual cycle influence on cognitive function and emotion processing-from a reproductive perspective. Frontiers of Neuroscience, 8, 380.

Sundstrom, I., Ashbrook, D., \& Backstrom, T. (1997). Reduced benzodiazepine sensitivity in patients with premenstrual syndrome: A pilot study. Psychoneuroendocrinology, 22(1), 25-38. https://doi.org/10.1016/S0306-4530(96)00035-2

van Goozen, S. H., Frijda, N. H., Wiegant, V. M., Endert, E., \& Van de Poll, N. E. (1996). The premenstrual phase and reactions to aversive events: A study of hormonal influences on emotionality. Psychoneuroendocrinology, 21(5), 479-497. https://doi.org/10.1016/0306-4530(95)00022-4

van Wingen, G., van Broekhoven, F., Verkes, R. J., Petersson, K. M., Backstrom, T., Buitelaar, J., \& Fernandez, G. (2007). How progesterone impairs memory for biologically salient stimuli in healthy young women. Journal of Neurosciences, 27(42), 11416-11423. https://doi.org/10.1523/JNEUROSCI.1715-07.2007

Wittchen, H. U., Becker, E., Lieb, R., \& Krause, P. (2002). Prevalence, incidence and stability of premenstrual dysphoric disorder in the community. Psychological Medicine, 32(1), 119-132. https://doi.org/10.1017/S0033291701004925

\section{Copyrights}

Copyright for this article is retained by the author(s), with first publication rights granted to the journal.

This is an open-access article distributed under the terms and conditions of the Creative Commons Attribution license (http://creativecommons.org/licenses/by/4.0/). 